\title{
Goodness of Fit Model Dependent Approaches of Controlled Release Matrix Tablets of Zidovudine
}

\author{
Snehamayee Mohapatra', Rajat Kumar Kar ${ }^{2 *}$ and Sunit Kumar Sahoo ${ }^{3}$ \\ 'Department of Pharmaceutics, SPS, S'O'A University, Bhubaneswar, Odisha, 751003, India. \\ 2Department of Pharmaceutics, Dadhichi College of Pharmacy, Cuttack, Odisha, 754002, India. \\ ${ }^{3}$ Department of Pharmaceutical Sciences, Utkal University, Bhubaneswr, 751004, India.
}

\begin{abstract}
Objectives: The objective of the study was to develop controlled release matrix tablet of zidovudine and to understand the release kinetics of drug by applying several mathematical model dependant and independent approaches. Various equations and models are developed for evaluating the drug release. Comparison of original and predicted release profile was most common way for selection of optimum formulation. Methods: In this study drug release profiles are characterized by using several parameters like percentage of drug released at $1 \mathrm{~h}$ and 12 $h\left(R_{1 h}, R_{12 h}\right)$, dissolution efficiency at $2 h$ and $12 h\left(D E_{2 h}, D E_{12 h}\right)$ and pair wise procedures such as similarity factor $\left(f_{1}\right)$, difference factor $\left(f_{2}\right)$ and rescigno indices $\left(\xi_{1}, \xi_{2}\right)$ for getting the optimum formulation. Six batches (C1 to C6) of different concentration of carbopol embedded controlled release matrix tablets of Zidovudine were evaluated. Further the criteria for selection of appropriate model was based on goodness of fit $\left(R^{2}\right.$, adj- $\left.R^{2}\right)$, sum square residual (SSR), F value and Akaike Information Criterion (AIC). Results \& Conclusion: Formulation C5 showed highest values of $\mathrm{DE}_{2 h^{\prime}} \mathrm{DE}_{12 \mathrm{~h}}(19.45 \%, 57.63 \%)$ with acceptance criteria of $f_{2}(51.63), f_{1}(9.91), \xi_{1}(0.063)$ and $\xi_{2}$ (0.066). Further, drug release from optimum batch $C 5$ was explained by the Higuchi model, due to highest value of $R^{2}(0.992)$, adj- $R^{2}(0.991)$ with lowest value of SSR (62.22), $F(5.65)$ and AIC (53.56) data. Moreover a simple mathematical equation was applied to determine the deviation of area under curve (AUC) between predicted and observed dissolution data. On an average of $13.4 \%$ percent deviation of AUC was observed in optimum batch.
\end{abstract}

Key words: Area under curve, Goodness of fit, Higuchi model, Matrix tablet, Sum square residual.

\section{INTRODUCTION}

In vitro dissolution has been recognized as an important element in drug development. Under certain conditions it can be used as a surrogate for the assessment of Bioequivalence.

Polymer swelling, erosion, drug dissolution/ diffusion characteristics, drug distribution inside the matrix, drug/polymer ratio and system geometry etc., have been used to predict the release behavior of drug from the embedded matrix tablet. ${ }^{1}$ Further, molecular weight, equilibrium water content, interaction with water, chain disentanglement and viscosity of the polymers determine the rate and mechanism of drug release from the controlled release matrix tablet. ${ }^{2}$

Hydrophilic matrix tablet is the simplest and most cost-effective method of fabricating controlled release solid oral dosage form.
Moreover, in such case the release pattern of drug is very controlled manner which is due to polymer hydration (glassy/rubbery transition) and dissolution of soluble components when interact with aqueous media (water, buffers, physiological fluids, etc.). ${ }^{3}$ Release retardant particularly anionic polymers such as carbopol has more influence in the drug release pattern from the matrices due to lowering the micro environmental $\mathrm{pH}$ in basic media and can also retard the drug release in acidic media by forming an insoluble mass that acts as a barrier to drug diffusion. ${ }^{4}$ Moreover, it provides excellent tablet hardness and low friability over a wide range of compression forces.

Several model dependent approaches such as zero-order, first-order, Higuchi, Hixson-
Submission Date :02-03-2015 Revision Date : :25-05-2015 Accepted Date : :26-06-2015

DOI: 10.5530/ijper.50.1.18 Correspondence Address Dr. Rajat Kumar Kar Department of Pharmaceutics, Dadhichi College of Pharmacy, Cuttack, Odisha, 754002, India.

Email:rajatkpharma@rediffmail.com

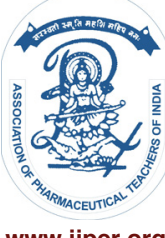

www.ijper.org 


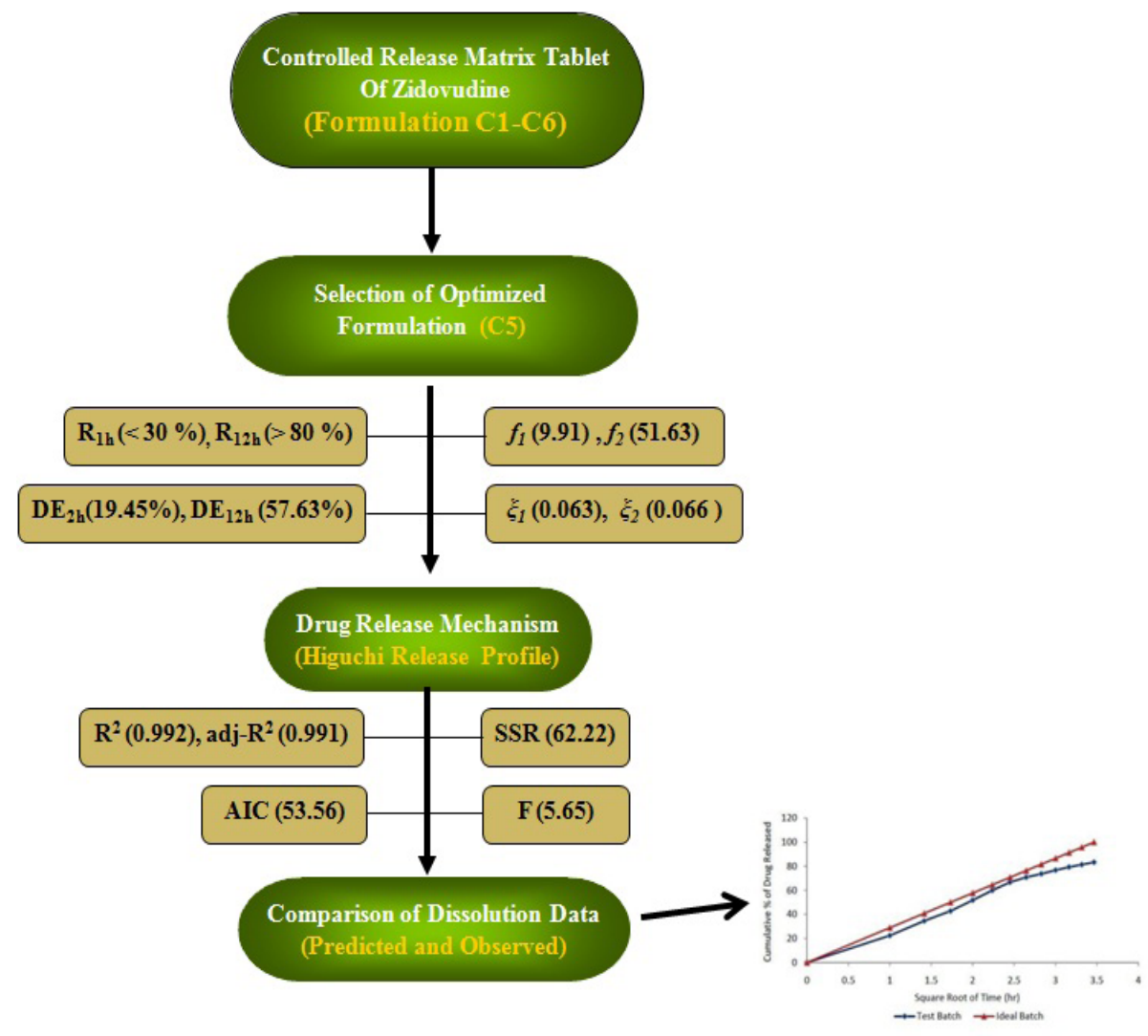

\section{Graphical Abstract}

Crowell, Weibull, Korsemeyer-Peppas, Baker-Lonsdale, Gompertz, Hopfenberg, quadratic, logistic, etc, have been used after linearization to predict the kinetics and mechanism of drug release from the intact matrices. ${ }^{5-10}$ Extensive research has been done to find goodness of fit model by considering coefficient of determination $\left(\mathrm{R}^{2}\right)$ as a parameter. ${ }^{11}$ According to J. Singh, et al. the above parameter couldn't be considered as goodness of fit statistics in both linear and nonlinear relationship. ${ }^{12}$ Now a day's multiple parameters such as $\mathrm{R}^{2}$, sum square residual (SSR), $F$ values are considered as the final criteria to be accounted for the selection of appropriate model. ${ }^{13}$ Further according to Gohel, et al. deviation of AUC from ideal release profile was also considerable for optimization of a formulation. ${ }^{14}$ Hence considerations of multiple parameters are highly desirable to consider the mechanism of drug release with least precision.

\begin{tabular}{|c|c|c|c|c|c|c|}
\hline Table 1: Formulation of Zidovudine SR Tablets using \\
Carbopol 971 P NF \\
\hline \multirow{7}{*}{ Ingredients } & \multicolumn{7}{|c|}{ Batch Number } \\
\cline { 2 - 7 } & C1 & C2 & C3 & C4 & C5 & C6 \\
\hline $\begin{array}{c}\text { Carbopol } \\
\text { (\%) }\end{array}$ & 10 & 15 & 20 & 25 & 12.5 & 10 \\
\hline EC (\%) & - & - & - & - & 12.5 & 15 \\
\hline
\end{tabular}

Zidovudine (AZT), the first anti-HIV compound approved for clinical use, which is widely used for treatment of AIDS either alone or in combination with other antiviral agents. AZT is absorbed throughout the GIT. ${ }^{12}$ Drug is freely soluble at any $\mathrm{pH}$ with high permeability; hence it is a good candidate for the development of controlled release oral dosage form. Further drug having above characteristics are ideal candidate for establishing IVIVC of their performance.

In the present research focus has been done for optimization of the formulation by quantitative evaluation of the parameters like dissolution efficiency (DE), pair wise comparison like similarity factor $\left(f_{2}\right)$, difference factor $\left(f_{1}\right)$, rescigno index $\left(\xi_{1}, \xi_{2}\right)$. Furthermore, analysis of several regression parameters such as $\mathrm{R}^{2}$, SSR, $\mathrm{F}$, adjusted coefficient of determination (Adj- $\mathrm{R}^{2}$ ) and Akaike Information Criterion (AIC) was done to get most appropriate model. Moreover deviation of the dissolution data was evaluated using AUC-based mathematical approaches.

\section{MATERIALS AND METHODS}

AZT was received as a gift sample from Mecleod's Pharma (Mumbai, India), Carbopol $934 \mathrm{P} \mathrm{NF}$ and Ethyl Cellulose were obtained from Dr Reddy's Lab 
(Hyderabad, India), Micro Crystalline Cellulose (MCC) and Mg. Stearate from Loba Chem (Mumbai, India). All other chemicals were of analytical grades as required.

\section{Preparation of sustained release matrix tablets}

Matrix embedded controlled release tablets of AZT were prepared by direct compression method using various concentrations of Carbopol $934 \mathrm{P} \mathrm{NF}$ alone or in combination with Ethyl cellulose (EC) (Table 1). $300 \mathrm{mg}$ of drug was taken in each batch with different percentage ratio of polymer(s). MCC was taken quantity sufficient to get $550 \mathrm{mg}$ of tablet. All ingredients except magnesium stearate were blended in glass mortar uniformly. After the sufficient mixing magnesium stearate $(6 \mathrm{mg} / \mathrm{tab})$ was added and mixed for additional 2-3 minutes. Finally compression was done in eight station tablet compression machine (rotary tableting machine, Rimek Minipress-I, India) using 12-mm punches.

\section{Physical Characterization of the Designed Tablet}

The properties of the compressed matrix tablets, such as hardness, friability, weight variation, and content uniformity were determined using reported procedure. ${ }^{13-15}$ Tablet hardness was tested by Monsanto hardness tester. Friability was determined by Roche friability test apparatus for $4 \mathrm{~min}$ at $25 \mathrm{rpm}$. The weight variation was determined by taking weight of 20 tablets using an electronic balance (Sartorious Electronic Balance, BT-2245). The drug content of the manufactured tablets of each batch was determined in triplicate. For each batch 20 tablets were taken, weighed and finely powdered. An accurately weighed quantity of this powder was taken and suitably dissolved in water, and analyzed after making appropriate dilutions.

\section{Dissolution study of the prepared formulations}

Dissolution studies of the matrix tablets were studied up to 12 hours using USP-22 type I dissolution apparatus. The dissolution medium was $900 \mathrm{ml}$ of $0.1 \mathrm{~N}$ hydrochloric acid for first 2 hours, distilled water for rest of the time maintained at $(37 \pm 0.5)^{\circ} \mathrm{C}$ of $50 \mathrm{rpm}$. Sample of $5 \mathrm{ml}$ was withdrawn at specific time intervals throughout the dissolution study for analysis and replaced with equal volume of fresh dissolution medium. Drug content was determined spectrophotometrically (V-570, Jasco, Tokyo, Japan) at $269 \mathrm{~nm}$.

\section{Model dependent approaches}

To study the release kinetics, data obtained from invitro drug release profile was plotted in various kinetic models: zero order, first order, Higuchi model, HixsonCrowell, Weibull, Korsemeyer-Peppas. ${ }^{16}$

Zero order $\quad Q_{t} / t \ldots \ldots \ldots 1$

First order $\quad \log Q_{t} / t \ldots \ldots . .2$

Higuchi $\quad Q_{t} / \sqrt{t} \ldots \ldots \ldots .3$

Korsemeyer-Peppas $\log \% Q_{t} / \log t \ldots \ldots \ldots .4$

Hisxon-Crowell $\sqrt[1 / 3]{Q_{t}} / t \ldots \ldots . .5$

Weibull Model $\quad \log \left[-\ln \left(1-Q_{t}\right)\right]=\boldsymbol{b} \log \left(t-\boldsymbol{t}_{t}\right)-\log \boldsymbol{a} \ldots \ldots \ldots .6$

(Where $\mathrm{Q}_{\mathrm{t}}$ is the amount of AZT released at time $\mathrm{t}, \mathrm{b}$ is the shape parameter and $\mathrm{a}$ is the scale parameter)

\section{Other release parameters}

Other parameters used to characterize drug release profile are sampling time and dissolution efficiency. Sampling time corresponds to the amount of drug dissolved in time $1 \mathrm{~h}$ and $12 \mathrm{~h}\left(\mathrm{R}_{1 \mathrm{~h}}, \mathrm{R}_{12 \mathrm{~h}}\right)$. The dissolution efficiency (DE) of a pharmaceutical dosage form is defined as the area under the dissolution curve up to certain time, $t$, expressed as a percentage of the area of the rectangle described by $100 \%$ dissolution in the same time. ${ }^{17}$

$$
D . E .=\frac{\int_{0}^{1} y \times d t}{y_{100} \times t} \times 100 \ldots \ldots . .7
$$

Where $y$ is the percent of drug dissolved at time $t$.

\section{Release profiles comparison}

Several Model-independent approaches were considered to comparing the drug release of test product with ideal Higuchi release profile. Pair-wise procedures such as difference factor, similarity factor and Rescigno index were considered for assessment of release profile within the acceptance limit.

The difference factor $\left(f_{1}\right)$ measures the percent error between the tu $11 \cdot$ : point

$$
f_{1}=\frac{\sum_{j=1}^{n}\left|\mathrm{R}_{j}-\mathrm{T}_{\mathrm{j}}\right|}{\sum_{j=1}^{n}\left(\mathrm{R}_{j}+\mathrm{T}_{j}\right) / 2} \times 100 \ldots \ldots .8
$$

Where $n$ is the sampling number, $R_{i}$ and $T_{j}$ are the percent dissolved of the references and test products at each time point $j$. The percent error is zero when the test and drug reference profiles are identical and increase proportionally with the dissimilarity between the two dissolution profiles.

The similarity factor $\left(f_{2}\right)$ is a logarithmic transformation of the sum-squared error of differences between the test $T_{j}$ and reference $R_{j}$ over all time points 


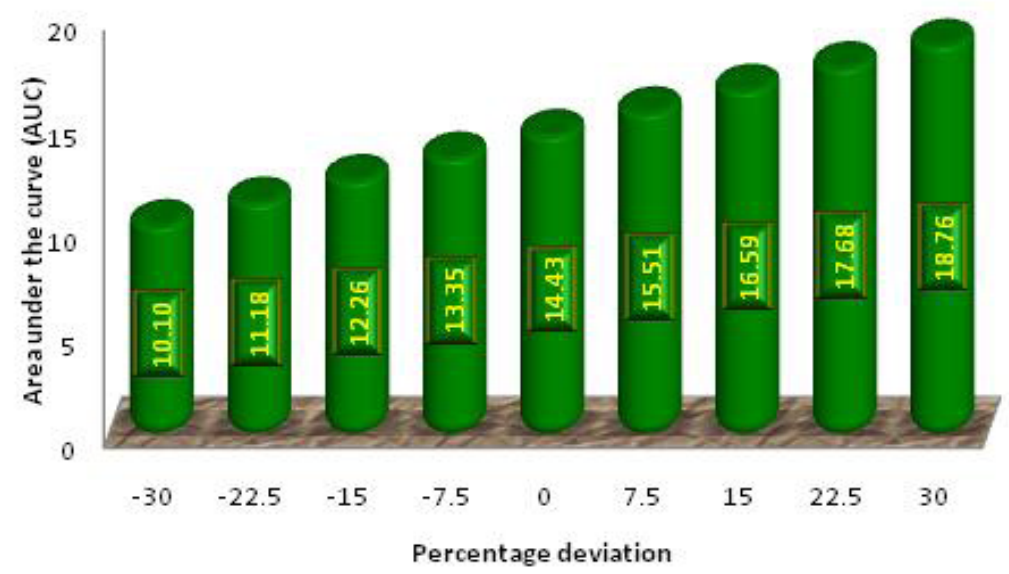

Figure 1: Relationship between AUC and percent deviation

Table 2: Physical Characteristics of Designed Controlled Release Matrix Tab-
lets of Zidovudine

\begin{tabular}{|c|c|c|c|c|}
\hline $\begin{array}{c}\text { Formulation } \\
\text { No. }\end{array}$ & $\begin{array}{c}\text { Avg. Wt. }(\mathrm{mg}) \\
\mathrm{n}=20\end{array}$ & $\begin{array}{c}\text { Hardness } \\
\left(\mathbf{k g} / \mathrm{cm}^{2}\right) \\
\mathrm{n}=10\end{array}$ & $\begin{array}{c}\text { Drug Content } \\
n=20\end{array}$ & $\begin{array}{l}\text { Friability } \\
(\%) n=10\end{array}$ \\
\hline C1 & $548.34 \pm 5.14$ & $7.01 \pm 0.28$ & $99.14 \pm 2.14$ & 0.562 \\
\hline $\mathrm{C} 2$ & $553.29 \pm 4.34$ & $7.13 \pm 0.33$ & $99.37 \pm 1.99$ & 0.579 \\
\hline $\mathrm{C} 3$ & $546.82 \pm 3.41$ & $6.48 \pm 0.22$ & $98.77 \pm 2.19$ & 0.575 \\
\hline C4 & $558.98 \pm 1.78$ & $7.86 \pm 0.23$ & $101 \pm 4.17$ & 0.509 \\
\hline C5 & $554 \pm 2.54$ & $6.56 \pm 0.34$ & $99.87 \pm 1.82$ & 0.554 \\
\hline C6 & $555.48 \pm 5.06$ & $6.96 \pm 0.642$ & $101 \pm 1.37$ & 0.587 \\
\hline
\end{tabular}

* Values are represented as mean \pm s.d. (triplicate)

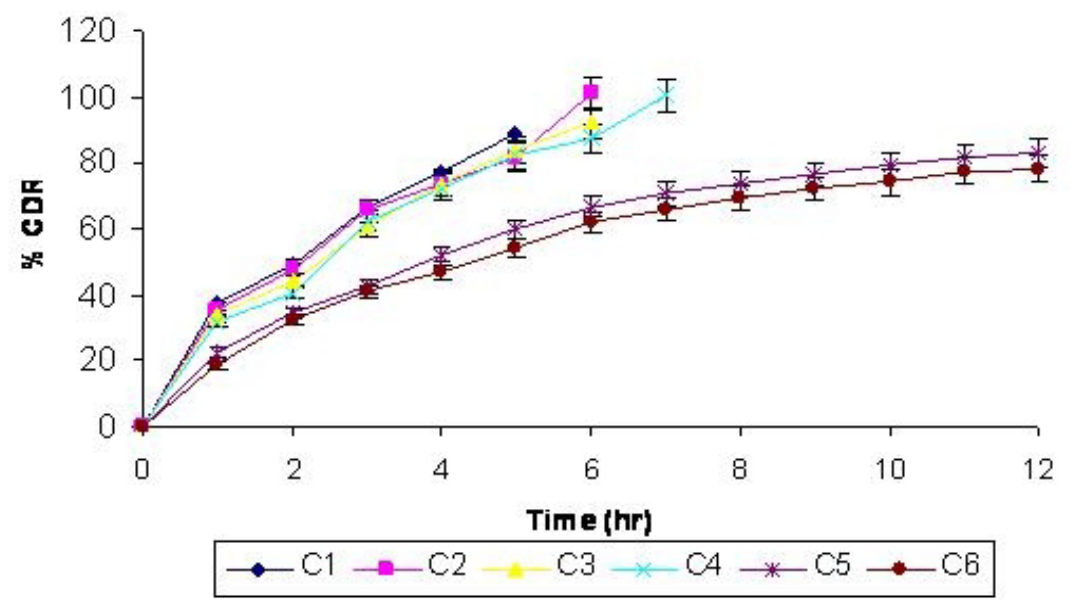

Figure 2: Dissolution release profile of different batches of matrix tablets

$$
f_{2}=50 \times \log \left\{\left[1+(1 / n) \sum_{j=1}^{n} w_{j}\left|\mathrm{R}_{\mathrm{j}}-\mathrm{T}_{\mathrm{j}}\right|^{2}\right]^{-0.5} \times 100\right\} \ldots \ldots . .9
$$

Where $\mathrm{W}_{j}$ is the optional weight factor and $\mathrm{n}$ is the number of pull point. The similarity factor fits with the result between 50 to100. ${ }^{18}$

Rescigno proposed a bioequivalence index to measure the dissimilarity between the test and reference product 
Table 3: Summary of experimental responses

\begin{tabular}{|c|c|c|c|c|c|c|}
\hline Batch & $\mathrm{DE}_{2 \mathrm{~h}}$ & $\mathrm{DE}_{12 \mathrm{~h}}$ & $f_{1}$ & $f_{2}$ & $\xi_{1}$ & $\xi_{2}$ \\
\hline $\mathbf{C 5}$ & 19.45 & 57.63 & 9.91 & 51.63 & 0.063 & 0.066 \\
\hline $\mathbf{C 6}$ & 17.43 & 54.51 & 17.89 & 43.83 & 0.098 & 0.099 \\
\hline
\end{tabular}

$$
\xi_{i}=\left\{\frac{\int_{0}^{\infty}\left|\mathbf{d}_{\mathrm{R}}(\mathbf{t})-\mathbf{d}_{\mathrm{T}}(\mathbf{t})\right|^{i} d t}{\int_{0}^{\infty}\left|\mathbf{d}_{\mathrm{R}}(\mathbf{t})+\mathbf{d}_{\mathrm{T}}(\mathrm{t})\right|^{i} d t}\right\}^{1 / i} \ldots \ldots . .10
$$

Where $d_{R}(t)$ is the reference dissolved amount, $d_{T}(t)$ is the test product dissolved amount at each sample point and $\mathrm{I}$ is the positive integer number. Two rescigno indexes generally created $\xi_{1}$ replacing the formula $i$ by 1 and $\xi_{2}$ replacing $i$ by $2 .{ }^{19}$

The Akaike Information Criterion is a measure of goodness of fit based on maximum likelihood. When comparing several models for a given set of data, the model associated with the smallest value of AIC is giving the best fit out of that set of models. ${ }^{16}$

$$
A I C=n \times \ln (\mathrm{WSSR})+2 \times \mathrm{p} \ldots \ldots \ldots 11
$$

Where, $n$ is the number of dissolution data points $p$ is the number of parameter of the model, WSSR is the weighed sum square residual.

\section{Mathematical Approach}

A novel approach of deviation from Higuchi model was proposed by Gohel et al. Which was used to evaluate deviation between predicted and observed dissolution profile of matrix formulation (Figure 1). ${ }^{20}$ The predicted percent of cumulative drug released (CDR) versus square root of time was considered as the reference line. The average absolute difference between AUCs (AADA) in $12 \mathrm{hr}$ system for residual was calculated by using equation 12 .

$$
A A D A \quad \alpha \%=\frac{n}{2 \times \sqrt{\boldsymbol{t}_{100}}} \times \alpha \ldots \ldots \ldots \quad 12
$$

Where $\mathrm{n}$ is the difference between two successive sampling points, $\mathrm{t}_{100}$ is the time to $100 \%$ drug release and $\alpha$ is the percent deviation.

Rewrite the equation taking ideal $12 \mathrm{~h}$ Higuchi release profile $\left(\mathrm{t}_{100}=12\right)$

$$
A A D A_{\alpha \%}=0.1443 \times \alpha \ldots \ldots .13
$$

\section{RESULTS AND DISCUSSION}

\section{Physical characterization of the designed tablets}

The prepared tablets were evaluated for weight-variation, friability, hardness and drug content, etc., according to the procedure specified in the Indian pharmacopoeia (Table 2). Uniform weight variation was observed $(<5 \%)$, hardness always remained within acceptable limits (between 6-7 $\mathrm{kg} / \mathrm{cm}^{2}$ ) depending upon compression force applied. High degree of drug content uniformity was found among different batches of tablets (more than $97 \%$ ) with friability was less $0.5 \%$ (wt/wt).

\begin{tabular}{|c|c|c|c|c|c|}
\hline \multicolumn{5}{|c|}{ Table 4: Report of the parameters found in various model } \\
\hline Model & $\mathbf{R}^{\mathbf{2}}$ & Adj-R & SSR & F & AIC \\
\hline Zero & 0.885 & 0.875 & 906.93 & 82.421 & 85.71 \\
\hline First & 0.895 & 0.876 & 766.02 & 69.63 & 83.68 \\
\hline Higuchi & 0.992 & 0.991 & 62.22 & 5.65 & 53.56 \\
\hline Hixson & 0.964 & 0.961 & 186.67 & 47.21 & 75.43 \\
\hline Korsmeyer & 0.985 & 0.984 & 137.23 & 25.31 & 69.23 \\
\hline Weibull & 0.968 & 0.987 & 78.63 & 7.86 & 58.97 \\
\hline
\end{tabular}

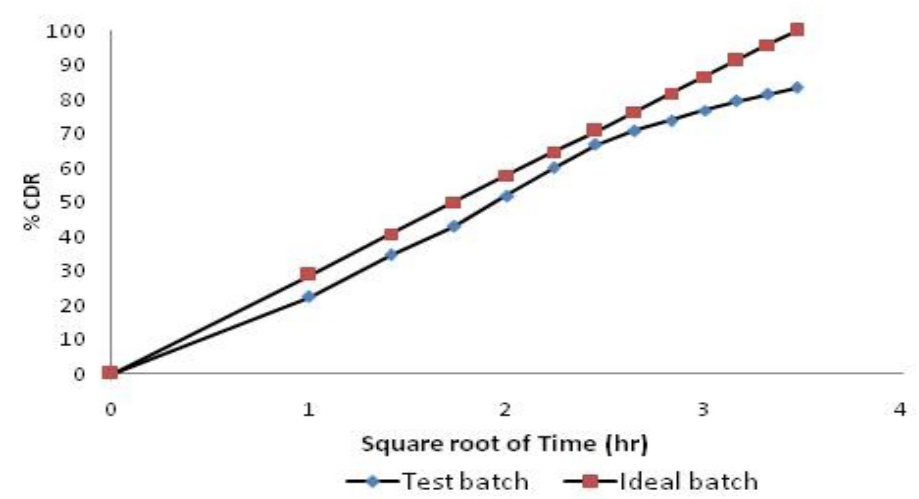

Figure 3: Comparison of dissolution profile of ideal and test batch 


\begin{tabular}{|c|c|c|}
\hline \multicolumn{2}{|c|}{$\begin{array}{c}\text { Table 5: Percentage deviation for the test prod- } \\
\text { uct from ideal Higuchi }\end{array}$} \\
\hline Time (hours) & $\begin{array}{c}\text { Absolute } \\
\text { difference in AUC }\end{array}$ & $\begin{array}{c}\text { \% deviation } \\
\text { from Higuchi } \\
\text { model }\end{array}$ \\
\hline $\mathbf{0}$ & 0 & 0 \\
\hline $\mathbf{1}$ & 3.22 & 22.314 \\
\hline $\mathbf{2}$ & 2.626 & 18.19 \\
\hline $\mathbf{3}$ & 2.131 & 14.768 \\
\hline $\mathbf{4}$ & 1.751 & 12.134 \\
\hline $\mathbf{5}$ & 1.238 & 8.58 \\
\hline $\mathbf{6}$ & 0.914 & 6.337 \\
\hline $\mathbf{7}$ & 0.936 & 6.487 \\
\hline $\mathbf{8}$ & 1.233 & 8.545 \\
\hline $\mathbf{9}$ & 1.525 & 10.57 \\
\hline $\mathbf{1 0}$ & 1.77 & 12.26 \\
\hline $\mathbf{1 1}$ & 2.03 & 14.07 \\
\hline $\mathbf{1 2}$ & 2.286 & 15.845 \\
\hline
\end{tabular}

\section{Drug release Analysis}

The selection criteria in the study was on the basis of $<30 \%$ drug release during first one hour of the study (for knocking out possibility of dose dumping), $>80 \%$ drug release up to last time period (almost complete release of the medicament).

The plot of cumulative percentage drug released versus time for embedded matrix tablets of AZT was prepared using different proportions of HPMC mentioned in the (Figure 2). 89.11 percent drug was released in five hours from formulation C1 (made-up of 10\% Carbopol), however in subsequent formulations the drug release gradually decreased as polymer concentration increased. In case of formulation C2 (containing 15\% Carbopol) the drug release was $101 \%$ in six hours. Similar condition was observed in formulations of C3, C4 (made up of $20 \%$ and $25 \%$ of polymer). This might be due to increase in viscosity of gel layer around the intact tablet. Drug release was significantly decreased when $25 \%$ of said polymer was used. However the dissolution profile of the above formulation extended up to seven hours. Moreover the above formulations were not satisfied the selection criteria as showing the dose damping. Further the release rate of formulation with maximum polymer (C4) was extended up to seven hours, which implies the poor retarding capability of the embedded polymer.

Hence to extend the drug release up to the maximum time period (12 h) hydrophobic polymer i.e., ethyl cellulose was included in the matrix tablet in order hinder the tortuous path.
Therefore, in the next batch (C5, C6), in order to control the initial burst effect, ethyl cellulose was incorporated in the matrix in the ratio of $1: 1$ and $1: 1.5$ with Carbopol. Thus, this binary mixture exhibited the result in extension of drug release for a period of $12 \mathrm{~h}$ (Figure 2). This might be due to more rigid complex formed by the polymer around the tablet core. Moreover, EC helped in retaining the drug in the intact matrix by preventing rapid diffusion of the soluble drug. ${ }^{21}$

Formulation C5 satisfied the conditions of selection criteria $\left(\mathrm{R}_{1 \mathrm{~h}}\right.$ and $\left.\mathrm{R}_{12 \mathrm{~h}}\right)$, less than $30 \%$ drug released in first one hour (no dose dumping) and more than $80 \%$ released in 12 hours. However incase of formulation C6 satisfied single condition of selection, $<30 \%$ drug released in first one hour $\left(\mathrm{R}_{1 \mathrm{~h}}\right)$. As very minute change in acceptance criterion was observed in $\mathrm{R}_{12 \mathrm{~h}}$ factor, hence other parameters such as $\mathrm{DE}_{2 \mathrm{~h}}, \mathrm{DE}_{12 \mathrm{~h}}$ with pair wise comparison of the above two batch were also considered as mentioned in (Table 3). From the data it was cleared that in both the time 2 hours and 12 hours the dissolution efficiency of formulation C5 was highest $57.63 \%$ and $19.45 \%$. Moreover, the similarity factor $f_{2}$ of the former formulation was found to be 51.63 which are within the acceptance limit (50-100) when compared with ideal Higuchi, but in case of the C6 batch deviation was observed as the value less than 50 (43.83). Further same result was found in $\mathrm{C} 5$ batch as dissimilarity factor $f_{1}$ is $9.91(0-10)$ where as $\mathrm{C} 6$ the value is 17.89 . Again the rescigno index $\left(\xi_{1}, \xi_{2}\right)$ of $\mathrm{C} 5$ formulation were found to be lower $0.063 \& 0.066$ which are approaching to zero implies the identity of test and reference. Hence considering these above parameters $\mathrm{C} 5$ was finalized as accepted batch on basis of release studied.

\section{Mechanism of drug release form matrix tablet}

The release data of selected batch was fitted to various model mentioned earlier. From multiple regression analysis various parameter such as coefficient of determination $\left(R^{2}\right)$, adjusted coefficient of determination (Adj- $R^{2}$ ), SSR, F and Akaike Information Criterion (AIC) were found as mentioned in the (Table 4). Analyzing the data it was revealed that, Higuchi model was best fit model due to highest $\mathrm{R}^{2}$ (0.992) with lowest value of $\mathrm{F}$ (5.65) and SSR (62.22). Further the adjusted coefficient of determination $\left(\mathrm{Adj}-\mathrm{R}^{2}\right.$ ) was very high (supporting to high significance of the model). Moreover, lowest value of Akaike Information Criterion (AIC) was also found in Higuchi model (53.56). Hence the Higuchi kinetic is the most appropriate mechanism of drug release.

From the observed dissolution data the calculated AUC was compared with the AUC of ideal Higuchi model (Figure 3). The absolute difference was observed by applying simple 
mathematical approach as mentioned in the equation 13. Maximum 22\% deviation was observed with an average of $13.64 \%$ indicating the proposed formulation has less release profile as compared to standard one (Table 5).

\section{CONCLUSION}

Release kinetic is an integral part of formulation development and the prerequisite for the establishment of IVIVC. Consideration of multiple factor for selecting goodness of value is more appropriate for selection process. Moreover it may give the genuine justification about the formulation development. Further choosing an optimized batch by considering only drug release characteristic not always give the precise data rather high degree of insignificance. Hence consideration of dissolution efficiency, pair wise comparison may lead to more appropriateness. From the above consideration batch $\mathrm{C} 5$ tablet composition complied with the controlled release profile criteria. Finally deviation in AUC to the release profile of the formulated product should be evaluated with the innovator in order to evaluate the errors of drug dissolution during formulation development stage.

\section{ACKNOWLEDGEMENTS}

Authors are thankful to Alkem Lab. (Mumbai, India) for providing gift sample of Zidovudine.

\section{CONFLICTS OF INTEREST}

There is no conflict of interest.

\section{ABBREVIATION}

$\begin{array}{ll}\text { CR } & \text { : Controlled Release } \\ \text { CDR } & \text { : Cumulative Drug Released } \\ \text { DE } & \text { : Dissolution Efficiency } \\ \text { AIC } & : \text { Akaike Information Criterion } \\ \text { SSR } & \text { : Sum Square Residual } \\ \text { AUC } & \text { : Area under curve }\end{array}$

\section{SUMMARY}

- Effect of Polymer swelling, erosion, drug dissolution/diffusion characteristics, drug distribution inside the matrix, drug/polymer ratio and polymer viscosity on drug release characteristics.

- Effect Micro environmental condition of Carbopol in different $\mathrm{pH}$ condition to hinder the drug release from intact matrices.

- Evaluation of drug release profile of controlled release matrix tablet Zivodune has been done using parameters like percentage of drug released at $1 \mathrm{~h}$ and $12 \mathrm{~h}\left(\mathrm{R}_{1 \mathrm{~h}^{\prime}}, \mathrm{R}_{12 \mathrm{~h}}\right)$, dissolution efficiency at $2 \mathrm{~h}$ and $12 \mathrm{~h}\left(\mathrm{DE}_{2 \mathrm{~h}^{\prime}}\right.$ $\mathrm{DE}_{12 \mathrm{~h}}$ ).

- Pair wise comparison such as similarity factor $\left(f_{1}\right)$, difference factor $\left(f_{2}\right)$ and rescigno indices $\left(\xi_{1}, \xi_{2}\right)$ has been done to get optimum formula.

- Further the release kinetics of the drug was evaluated by goodness of fit model using $R^{2}$, adj- $R^{2}$, sum square residual (SSR), F value and Akaike Information Criterion (AIC).

- Deviation of release profile of optimized batch from ideal Higuchi was also observed .

\section{About Authors}

Snehamayee Mohapatra: Working as Asst. Professor in Department of Pharmaceutics, SPS, S'O'A University, Bhubaneswar, Odisha, 751003, India. She has 20 no. of journal paper with 25 abstract.

Dr. Rajat Kumar Kar: Working as Associate Professor in Department of Pharmaceutics, Dadhichi College of Pharmacy, Cuttack; Under Biju Patanaik University of Technology, Odisha. He has more than 23 no. of journal paper with 30 no of abstract.

Dr. Sunit Kumar Sahoo: Working as Asst. Professor in Department of Pharmaceutical Sciences, Utkal University, Bhubaneswr; 751004; India. He has more than 30 journal with 40 no. of abstract.

\section{REFERENCES}

1. Colombo P, Bettini R, Castellani PL, Santi P, Peppas NA. Drug volume fraction profile in the gel phase and drug release kinetics in hydroxypropylmethyl cellulose matrices containing a soluble drug. Eur J. Pharma. Sci. 1999; 9(1): 33-40.

2. Narasimhan B, Peppas NA. Molecular analysis of drug delivery systems controlled by dissolution of polymer carrier. J. Pharma. Sci. 1997; 86(3): 297-304.

3. Huang $X$, Brazel CS. On the importance and mechanisms of burst release in controlled drug delivery- a review. J Control Release 2001; 73(2): 121-36.

4. Samani SM, Montaseri $\mathrm{H}$, Kazemi A. The effect of polymer blends on release profiles of diclofenac sodium from matrices. Eur. J. Pharm. Biopharm. 2003; 55(3): 351-5.
5. Lazarus J, Cooper J. Absorption, testing, and clinical evaluation of oral prolonged action rugs. J Pharm Sci. 1961; 50(9): 715-32.

6. Wagner JG. Interpretation of percent dissolved-time plots derived from in vitro testing of conventional tablets and capsules. J Pharm Sci. 1969; 58(10): 1253-7.

7. Higuchi T. Mechanism of sustained action medication: theoretical analysis of rate release of solid drugs dispersed in solid matrices. J Pharm Sci. 1963; 52(12): 1145-9.

8. Korsemeyer R, Gurny R, Peppas N. Mechanisms of solute release from porous hydrophilic polymers. Int J Pharm. 1983; 15(1): 25-35. 
9. Hixson AW, Crowell JH. Dependence of reaction velocity upon surface and agitation (I) theoretical consideration. Ind J Chem Eng. 1931; 23(10): 923-31.

10. Langenbucher F. Linearization of dissolution rate curves by the inert monolithic device with a central hole for constant drug release. Weibull distribution. J. Pharm. Pharmacol. 1972; 24(2): 979-81.

11. Mesnukul A, Phaechamund T. Drug release through PEG-xanthan gumlactose matrix comparing different amount of drug. Thai. Pharm. Sci. 2009; 86(4): 297-304.

12. Salsa T, Veiga F, Pina ME. Oral controlled-release dosage forms. I. Cellulose ether polymers in hydrophilic matrices. Drug Dev Ind Pharm. 1997; 23(9): 929-38

13. Indian Pharmacopoeia Commission. Indian Pharmacopoeia. Vol. 2. The Controller of Publications, New Delhi; 1996. 735.

14. Indian Pharmacopoeia Commission. Indian Pharmacopoeia. Vol. 1. The Controller of Publications, New Delhi; 1996. 242.
15. Lechman L, Liberman HA, Kanig JL. The Theory and Practice of Industrial Pharmacy. $3^{\text {rd }}$ ed. Varghese Publishing House, Mumbai; 1991. 88.

16. Costa P, Lobo J. Modeling and comparison of dissolution profiles. European Journal of Pharmaceutical Sciences 2001; 13(2): 123-33.

17. Khan KA. The concept of dissolution efficiency. J Pharm Pharmacol. 1975; 27(1): 48-9.

18. Moore JW, Flanner HH. Mathematical Comparison of Dissolution Profiles. Pharmaceutical Technology 1996; 20(6): 64-74.

19. Rescigno A. Bioequivalence. Pharm. Res. 1992; 9(4): 925-8.

20. Gohel CM, Panchal MK, Jogani VV. Novel Mathematical Model for quantitative expression of Deviation from the Higuchi model. AAPS Pharma Sci Tech. 2000; 1(4): 20-5.

21. Katikaneni PR, Upadrashta SM, Neau SH, Mitra AK. Ethylcellulose matrix controlled release tablets of a water-soluble drug. Int. J. Pharm. 1995; 123(1): 119-25. 